\title{
Humanistic PE-Current Practice of Physical Education in Colleges and Universities
}

\author{
Wei Dai \\ Physical Education College, Sichuan University of Science and Engineering, Zigong, 643000, China
}

Keywords: Humanistic PE. Physical Education in Colleges and Universities. Humanistic Spirit. Necessity. Strategy

\begin{abstract}
Both the emergence and dissemination of thoughts of Humanistic PE challenge the traditional teaching model of $\mathrm{PE}$ in colleges and universities and it is an urgent need for colleges and universities to explore the teaching model of Humanistic PE to show the respect to human being and to promote the construction of harmonious society. In the cultivation of talents, PE can not only promote the cultivation of healthy personality and improve physical quality of students, but also promote the cultural construction of campus and improve the image of colleges and universities The author firstly analyzes the connotation of Humanistic PE and then elaborates the necessity of the implementation of Humanistic PE in colleges and universities and lastly comes up with several suggestions for the implementation of Humanistic PE in colleges and universities.
\end{abstract}

\section{Overview of Humanistic PE}

$\mathrm{PE}$ is a practice which can help people to enhance physical fitness and transform physical function to adapt to the social development; from the aspect of spiritual realm, PE is a humanistic practice that human initiatively transform his mental state, and it contains lavish Humanity. So, PE is a integrated discipline combining of natural sciences and humanities.

Humanistic PE attaches importance to people oriented teaching activities, comprehending sport activities in accordance with students'features and using the teaching method of PE accepted by students and it emphasizes on understanding the profound meaning of PE from a broader sense, which can make the students understand that sports is not only a tool to build up a good physique but also an external expression of human way of life and even the way of existence. Humanistic PE lays stress on the harmonious development of body and mind. People take part in sports is not only the need of exercise, it also contains the pursuit of personal value and the need of process of socialization. Humanistic PE underlines people foremost, puts emphasis on understanding PE from the point of human beings, thinking highly of every single one in society,developing the human nature and boosting the sports.

What emerged together with Humanistic PE are how to carry out Humanistic PE and how to realize the people-oriented spirit of promoting human nature. $\mathrm{PE}$ is closely related to the socialization process of everyone and every individual in society should know how to promote the health development physically and mentally and utilize the sports to realize coordinated development of body, mind and spirit in real life.

\section{Necessity of the Implementation of Humanistic PE in Colleges and Universities}

Colleges and universities are the places of cultivating talents, which sent a lot of talents of all professions and trades to the society and promote the social progress and economic development. PE is a important part of college education which is related to the quality of talent cultivation.

Humanistic Physical Education in colleges and universities is an inevitable requirement of the times and social progress. Early in 1994, Chinese government had clearly put forward to promote the humanistic spirit and promote social progress in China Agenda 21. Today, the concept of sustainable development has been deeply rooted in people's hearts and the return of humanistic spirit would place the humanistic education on a very important position. Humanistic education in colleges and 
universities is an inevitable demand of the times, and also responsibility of colleges and universities which is given by the times.

The implementation of Humanistic PE in colleges and universities is an inevitable choice of talent cultivation in 21st century. Knowledge is the first productive force, and the 21st century is the era of knowledge economy, where human resources play a prominent role in social development. Universities and colleges are strongholds of personnel training, and physical education is an important part of their teaching activities, which plays an important role in promoting the overall development of the people, forming a positive and optimistic attitude towards life and improving psychological diathesis and physical quality. So it is an inevitable choice for universities and colleges to implement Humanistic PE.

It is an inherent demand of teaching activities in colleges and universities to carry out Humanistic PE. Today, the purpose of college physical education is to train students to become highly qualified personnel with physical fitness, mental health and healthy personality, which just happens to coincide with the connotation of Humanistic PE. Therefore, the implementation of Humanistic PE is very necessary, which can promote the overall development of students and the cultivation of humanities.

\section{Strategies for the Implementation of Humanistic PE in Colleges and Universities .}

To implement Humanistic PE requires colleges and universities to follow the people-oriented principle and carry out cultural penetration all the time, turning the physical education into a special activity of a rich cultural heritage and promoting the comprehensive development of students. By making a comprehensive survey of physical teaching activities in colleges and universities, we can find that humanities of teachers is not high, the enthusiasm of students to participate in sports activities is low, the students do not understand the meaning of the humanities of sports and physical education is far from reaching its preset goal. Competitive sports is still the main method of PE, which pays too much attention on students' mastery of motor skills, ignoring the penetration of humanistic knowledge and the cultivation of healthy personality of students, so the effect is poor. In today's society, universities must recognize the importance of the Humanistic PE, learn the connotation and related knowledge of Humanistic PE carefully, build teaching system of Humanistic PE based on the actual situation of teaching and student characteristics, training modern innovative talents who are also integrated.

\subsection{Strengthen the Penetration of Humanistic Content}

Humanities PE requires teachers to respect each student's personal values, to promote freedom and harmonious development of every student, and to promote the overall development of students. Trying to arouse the enthusiasm and initiative of students to participate in sports activities to let them feel the fun in physical activities and the joy of being a human being, thereby to enable students to enhance confidence and interest in learning and promote the smooth development of teaching and learning activities to improve teaching effectiveness.

Teachers in colleges and universities should recognize the importance of the penetration of humanistic content, change the traditional teaching philosophy,cultivate every student to be a person of ability and respect each student's personality, interests, hobbies, values, etc., so that students can learn more health knowledge, sports knowledge and safety knowledge. Teachers should guide students to grow and cultivate students' personality by sports activities.

\subsection{Optimization of Curriculum}

In the traditional PE model, PE Curriculum is common, and the content of PE is identical to almost all non-sports majors, which takes the competitive sports as the main teaching content. Humanistic PE requires gym teachers in colleges and universities to change their teaching philosophy as soon as possible, to improve the quality of Humanities and physical quality and optimize curriculum.

First, colleges and universities should offer PE basic courses, professional courses, elective courses, public courses, interdisciplinary elective courses and other sports courses for students. The system of physical education curriculum should be divided into four parts: humanistic PE, physical 
health, mental health and social health, which will help teachers to take humanistic content into physical education activities consciously and designedly, and promote the overall development of students.

Second, colleges and universities should choose proper teaching content. Colleges and universities should find out the most basic, the most humanistic sports basic knowledge, technical knowledge and basics, which is worthy of transferring, from vast amounts of sports knowledge. The principles of choice can reflect comprehensive, humanistic, cross-cutting nature of sports knowledge of sports disciplines. Colleges and universities should select teaching content in accordance with the teaching goal of Humanistic PE, eliminate outdated, backward sports knowledge which does not match the target of personnel training and stimulate students' interest in learning, improve the effectiveness of PE in a short time.

Third, colleges and universities should enrich the physical education curriculum. Modern college students have different interests and different hobbies, so their requirements towards PE are not the same. In order to promote the overall development of students, schools should actively enrich physical education curriculum, so that students can choose the appropriate physical education curriculum according to their needs. Colleges and universities should meet students' individual needs and promote their healthy development.

Of course, no matter what the course is or what the teaching content is, the people-oriented philosophy is the most fundamental, physical education teachers should always hold the belief of penetration of humanistic knowledge. For example: when teaching martial arts, teachers can talk to students about the origin and development of Chinese martial arts, about the spiritual content of each action, which can cultivate national pride and self-esteem of students. Another example: to ask students to simulate football, basketball, volleyball, badminton, running and other athletic sports can hone students' psychological quality, cultivate social and moral law-abiding concept and promote students to develop the belief that "the most important thing is to participate".

\subsection{Establishment of Teacher-students Relationship of Humanistic Care}

A good teacher-student relationship can stimulate students' interest and desire of study. PE teachers in colleges and universities should adhere to the people-oriented principle, love and respect students, concern about the students, establish equal, harmonious relationship with students in which teachers and students respect each other and create a good atmosphere for teaching in the teaching activities, so that all students can learn theoretical knowledge of sports in a relaxed, open atmosphere, participate in sports activities and achieve physical and mental health development.

Teachers should be fair to every student, be good at digging the potentialities of students and find the bright spot of students. They should also encourage students to develop their personality, increase students' enthusiasm of study and optimism and meet the student's curiosity. For example: in the teaching activities, teachers should respect students' interests and hobbies, teach students in accordance with their aptitude in a real sense and promote the free development of each student from the aspects of health and safety.

Teachers should create lavish humanistic teaching classrooms, construct an open classroom atmosphere to attract students' attention and eyeballs to promote students to participate in sports activities actively and learn sports knowledge, knowledge of health, knowledge of safety and so.

Teachers should enhance the communication with students, make friends with the students and establish good teacher-student relationships.

\subsection{Creation of A Good Humanistic Environment of PE}

Teaching is not a simple classroom activity, it occurs in a certain social environment. For the teaching of Humanistic PE in colleges and universities, the good campus environment is an important method and way to improve the effects of physical education. Colleges and universities should start from the stadium, the sports environment and the cultural atmosphere to construct humanistic environment of sports and to let the humanistic environment influence students in long-term, nurturing students' humanistic spirit of sport.

Colleges and universities should carry out all kinds of lively humanistic sports activities, such as: sports clubs, sports academic salon, sports knowledge quiz and other campus activities to promote the 
spirit of sport and to improve students' humanistic consciousness for sports . Colleges and universities should spread humanistic sports ideas, and create a strong sports culture on campus through the school newspaper, campus network, posters, radio and other forms, enabling students to develop good sportsmanship habits subtly.

Colleges and universities should take Humanistic Olympics as an opportunity to carry out extensive research of sports activities. Humanistic Olympics is not a simple sports + culture, it contains rich spirit of humanistic spirit of sports. Colleges and universities should make full use of their personnel and technological strength, look Humanistic Olympics as scientific research project, produce more achievements of study, and promote construction of humanistic environment for sports on the campus.

\subsection{Strengthen the Impartation of Theoretical Knowledge}

Traditional Physical Education focus on motor skills training of students, but the Humanistic PE is more valued personality development of students, so we should focus on imparting theoretical knowledge. In most colleges and universities, teaching of theoretical knowledge of sports account for less than $20 \%$ of teaching and faculty leaders and leaders believe that theoretical knowledge of sports is not practical, and students are unwilling to learn it. In fact, teaching theoretical knowledge of sports is an important feature of Humanistic PE, teachers should use a wide range of teaching methods to enrich teaching model of theoretical knowledge of sports to stimulate students' interest and desire of study and to promote the smooth development of teaching and learning activities.

\subsection{Diversity of Teaching Methods}

The traditional approach to physical education teaching mainly focuses on teaching, indoctrination and demonstration, students' initiative has been curbed, which is not conducive to the development of students' personality. In this new era, colleges and universities should actively explore new educational methods, attempt to apply teaching methods of other disciplines, such as the question teaching method, situational teaching method, cooperative teaching method, and case teaching method to the Physical Education to stimulate students' curiosity and desire of participation and improve the effect of PE.

Teachers should use modern science and technology to enrich teaching and learning activities, such as: using video teaching method to make teaching activities become more vivid, more detailed and livelier, stimulating students' curiosity. Another example: to carry out all kinds of new sports activities and introduce health sports, leisure sports, expanded sports to the PE in colleges and universities. And another example: teachers can disseminate personal history and the spirit of struggle of students' favorite sports star to stimulate student interest in learning.

\subsection{Construction of Scientific Evaluation Mechanism of PE}

Firstly, the subjects of evaluation should be diversified, which is combined by the self-evaluation and evaluation of others. There are not only both teachers' and students'evaluation, but also evaluation of faculty leadership, as well as evaluation of experts.

Secondly, the content of evaluation should be abundant. Not only the mastery of motor skills and sports knowledge of students should be taken into consideration, but also the interest, attitude, emotion, humanities, knowledge of health and safety of students should be evaluated.

Thirdly, evaluation methods should be diversified. Qualitative and quantitative evaluation methods should be used together and evaluation of the results and evaluation of the process should be combined.

\section{Conclusion}

Colleges and universities are personnel training base, the breeding base of the Humanistic PE, the birth place of a variety of recreational PE, healthy PE and expended PE. The implementation of Humanistic PE is the responsibility of colleges and universities and it is the inevitable choice of personnel training in colleges and universities. Leaders in colleges and universities must strive to improve the humanities of physical education teachers, push them to change the teaching philosophy, increase the investment in Physical Education, gradually promoting the Humanistic PE. The author, 
in terms of curriculum, teaching content, teaching methods, teacher-student relationship, evaluation mechanisms and humanistic environment, elaborated the strategies of implementation Humanistic PE in colleges and universities in the hope of promoting the transformation of PE in colleges and universities and training more new talent.

\section{References}

[1] Yang Kewen. Strategies of Implementation of Humanistic PE in Colleges and Universities. Urban Tutor: 2013(8).

[2] Zuo Bin. Humanistic Spirit in PE in Colleges and Universities. Business: 2013(6).

[3] Zhang Tao. Strategies of Construction of Humanistic PE Value in Vocational PE. Knowledge Economy: 2011(24).

[4] Zhang Kebin. Role of Humanistic PE in the Sustainable Development of PE in Colleges and Universities. Journal of Xingtai University: 2012(2).

[5] Wang Yuan. Dissemination of the Concept of Humanistic PE, Building Brand of PE in Colleges and Universities. Industry Market: 2007(12).

[6] Lu Huan. Theory of Penetration of Humanistic Spirit in PE in Colleges and Universities. Northeast Normal University, 2010. 